\title{
Variasi Sapaan Ragam Akrab dan Ragam Santai Masyarakat Melayu Jambi dalam Komunikasi Verbal (Kajian Sosiolinguistik)
}

\author{
Ade Rahima \\ Universitas Batanghari Jambi, Indonesia \\ Correspondance email: ade.rahima@unbari.ac.id
}

\begin{abstract}
Abstrak. Tujuan dalam penelitian ini adalah untuk mendeskripsikan varasi sapaan wacana ragam akrab dan ragam santai dalam komunikasi verbal masyarakat melayu Jambi. Fokus penelitian terkait 3 hal yakni: 1) bentuk-bentuk variasi sapaan wacana ragam akrab dan ragam santai, 2) faktor-faktor yang melatarbelakangi timbulnya variasi sapaan dalam wacana ragam, dan 3) pola kalimat yang mengandung variasi sapaan wacana ragam akrab dan ragam santai dalam komunikasi verbal masyarakat Melayu Jambi. Penelitian ini merupakan penelitian kualitatif dengan pendekatan sosiolinguistik. Pengumpulan data lapangan menggunakan metode etnografi. Tenik etnografi yang digunakan mencakup observasi partisipatif, in-depth interview, introspeksi, dan analisis domein. Data primer berasal dari 8 orang informan dan data skunder berasal dari dokumen. Data dianalisis berdasarkan faktor sosial budaya dan situasional. Berdasarkan hasil dan pembahasan dapat disimpulkan bahwa: 1) Bentukbentuk variasi sapaan dalam komunikasi verbal masyarakat Melayu Jambi terdapat dalam ragam akrab dan ragam santai. Bentuk sapaan yang digunakan antara lain pangilan kesanyangan, singkatan nama, panggilan akrab dan panggilan khusus di luar bahasa. Variasi ini ditemukan dalam komunikasi verbal antaranggota keluarga baik kepada yang lebih tua, sama besar, atau lebih kecil. Variasi sapaan ragam akrab dan ragam santai di luar hubungan keluarga terjadi pada sahabat karib atau teman dekat biasanya mengunakan panggilan khuusus. 2)Faktor-faktor penyebab penggunaan variasi sapaan ragam akrab dan ragam santai dalam komunikasi verbal ditentukan oleh faktor kedekatan hubungan penutur dan petutur, situasi tuturan dan serta topik tuturan 4) Pola kalimat ragam akrab cendrung Subjek-Predikat (S-P) sedangkan ragam santai Peredikat-Objek (P-O).
\end{abstract}

Kata Kunci: Sapaan, Ragam Akrab, Ragam Santai, Bahasa Melayu Jambi

\begin{abstract}
The purpose of this research is to describe the familiar and relaxed variety of speech greetings in the Malay community of Jambi. The focus of the research is related to 3 things, namely: 1) the forms of various forms of addressing familiar and casual types of discourse, 2) the factors behind the variations in addressing variations in various discourses, and 3) sentence patterns that contain variations in addressing familiar and casual types of discourse. in the verbal communication of the Jambi Malay community. This research is a qualitative research with a sociolinguistic approach. Field data collection uses ethnographic methods. Ethnographic techniques used include participatory observation, in-depth interviews, introspection, and domine analysis. Primary data comes from 8 informants and secondary data comes from documents. Data were analyzed based on sociocultural and situational factors. Based on the results and discussion, it can be concluded that: 1) The forms of variation of greetings in the verbal communication of the Jambi Malay community are in the familiar and casual types. Forms of greeting used include pangilan kesanyangan, name abbreviations, intimate calls and special calls outside the language. This variation is found in verbal communication between family members whether they are older, the same age, or less. The variety of friendly and casual types of greetings outside of family relationships occurs in close friends or close friends, usually using special calls. 2) The factors that cause the use of familiar and casual types of greetings in verbal communication are determined by the factor of the proximity of the speaker and speaker relationship, the situation of speech and the topic of speech 4) The sentence pattern of the familiar variety tends to be Subject-Predicate (SP) while the casual variety Object (PO).
\end{abstract}

Kata Kunci: Greetings, Variety of Familiar, Variety of Casual, Jambi Malay

\section{PENDAHULUAN}

Dalam kehidupan sehari-hari manusia akan menggunakan bahasa sebagai alat untuk berkomunikasi. Hal yang menarik untuk diamati yaitu cara-cara yang digunakan manusia dalam berkomunikasi termasuk cara berdiam (tidak berbicara). Mashall dalam Wardhaugh, (2006:242--243) menjelaskan bagaimana suatu masyarakat penutur memiliki kebiasaan tertentu dalam menghindari perpecahan dan permusuhan di dalam kelompok atau antarkelompoknya. Dalam berkomunikasi atau berinteraksi variasi berbicara ragam akrab merupakan salah satu bentuk variasi bahasa yang hampir setiap saat digunakan penuturnya. Dengan menggunakan variasi tersebut maka akan terjalin keakraban dan mitra tutur dapat mengetahui arah dan maksud pembicaraan. Dengan kata lain keberhasilan menyampaikan informasi dalam komunikasi juga dapat ditentukan oleh variasi bicara yang digunakan pada saat berkomunikasi. Menurut Chair, (2004:62) ada 2 pandangan tentang variasi atau ragam bahasa: 1) variasi atau ragam bahasa terjadi sebagai akibat adanya keragaman sosial penutur bahasa dan keragaman fungsi bahasa itu. 2) Variasi atau ragam bahasa itu sudah ada sebagai alat interaksi dalam kegiatan masyarakat yang beraneka ragam.

Setiap penutur tentu memiliki variasi bicara yang berbeda atau beragam. Variasi bahasa merupakan pilihan bahasa atau penunaan bahasa selompok masyarakat merupakan kajian bidang sosiolinguistik. Hal ini mengacu pada 
pendapat Bell dalam rahima (2013:2) bahwa kajian variasi bahasa dalam sosiolinguistik terkait dengan pilihan bahasa dan pengunaan bahasa suatu masyarakat. Keragaman atau variasi tersebut akan semakin tampak jika digunakan oleh penutur yang banyak serta dalam kawasan wilayah yang cukup luas, misalnya bahasa Melayu Jambi. Bahasa Melayu jambi sebagai bahasa daerah yang hidup dan berkembang di tengah-tengah masyarakat penuturnya, mempunyai kedudukan yang sama dengan bahasa-bahasa daerah lain. Namun karena kuatnya pengaruh bahasa lain baik bahasa daerah maupun bahasa asing, banyak kosa kata daerah lain dan bahasa asing yang diterima dan digunakan oleh masyarakat desa di Provinsi Jambi khususnya masyarakat melayu Jambi. Fenomena ini menyebabkan muncilnya variasi bahasa, Salah satu unsur kosa kata yang terpengaruh adalah kata sapaan. Berdasarkan hasil pantauan peneliti terhadap hal ini, maka ditemukan berbagai variasi sapaan yang digunakan dalam wacana ragam akrab dan wacana ragam santi, contohnya sapaan akranb untuk seorang ayah digunakan kata Abi, Buya, dan Abah, Apa. Sedangkan untuk ibu disapa dengan sapaan akrab Umi, Mamak, Bundo.

Salah satu bentuk variasi berbicara dilihat dari segi tingkat keformalan ragam akrab dan ragam santai. Bentuk variasi wacana ragam akrab dan santai dalam bahasa Melayu Jambi di Desa Mendalo Indah Kecamatan Kabupaten Muarojambi menjadi menarik diteliti karen memiliki keunikan dan variatif dalam ragam berbicara penuturnya. Selain itu, secara geografis Desa Mendalo Indah Muarojambi letaknya di daerah kampus yakni kampus Universitas jambi dan kampus Universitas Islam, variasi tersebut terpengaruh oleh bahasa-bahasa pendatang yang dibawa oleh mahasiswa dari berbagai daerah lain yang bukan beerbahasa Melayu Jambi.

Berdasarkan latar belakang tersebut, peneliti tertarik untuk mengkaji masalah variasi sapaan bahasa Bahasa Melayu Jambi dengan judul: Variasi Sapaan Wacana Ragam Akrab dan Ragam santai pada Masyarakat Melayu Jambi di Desa Mendalo Indah, Kecamatan Jambi Luar Kota, Kabupaten Muarojambi. Fokus masalah terkait dengan aspek bentuk, fungsi dan pola urutan variasi sapaan tersebut. Oleh karena itu, tujuan penelitian ini untuk mendeskripsikan: 1) Bentuk-bentuk variasi sapaan ragam akrab dan ragam santai dalam komunikasi verbal masyarakat Melayu Jambi. 2) Faktor-faktor apa saja yang mempengaruhi penggunaan variasi sapaan ragam akrab dan ragam santai dalam komunikasi verbal masyarakat Melayu Jambi. 3) Bagaimana pola urutan kalimat dalam wacaana ragam akrab dan ragam santai masyarakat Melayu Jambi.

\section{Landasan Teori}

Variasi bahasa merupakan salah satu kajian utama dalam bidang sosiolinguistik. Hal ini mengacu pada pendapat Chaer, (2004-61) yang menjelaskan bahwa "Variasi atau ragam bahasa merupakan bahasan pokok dalam sosiolinguistik". Variasi bahasa terjadi karena penutur bahasa itu tidak homogen dan kegiatan interaksi sosial yang dilakukan sangat beragam. "Ragam bahasa terbagi menjadi empat macam yaitu ragam dari segi penutur, ragam dari segi pemakaian, ragam dari segi keformalan, dan ragam dari segi sarana" (Chaer, 2004:62-72). Sesuai dengan judul penelitian maka peneliti hanya akan membahas ragam bahasa dari segi keformalan karena dalam ragam bahasa dari segi keformalan terdapat ragam akrab. "Ragam bahasa dari segi keformalan terdiri atas ragam beku, ragam resmi, ragam usaha, ragam santai, dan ragam akrab" (Martin Joos dalam Chaer, 2004:70). Ragam beku adalah variasi bahasa yang paling formal misalnya dalam upacara, khutbah jum'at, dan lain-lain. Ragam resmi adalah variasi bahasa yang biasanya digunakan dalam rapat, surat dinas, dan lain-lain. Ragam usaha adalah variasi bahasa yang biasanya digunakan dalam pembicaraan yang berorientasi kepada hasil atau produksi. Ragam santai adalah variasi bahasa yang digunakan dalam situasi tidak resmi untuk berbincang-bincang dengan keluarga, teman karib, dan lain-lain. Ragam akrab adalah variasi bahasa yang biasa digunakan para penutur yang hubungannya sudah akrab, seperti antaranggota keluarga, dan antarteman yang sudah karib.

Selain itu, menurut Chaer, (2004:71) ragam akrab dan ragam santai ditandai oleh struktur kalimat yang pendek, penggunaan bahasa yang tidak lengkap, dan istilah khusus serta cenderung santai. Hal ini terjadi karena di antara penutur dan penaggap tuturnya sudah kedekatan, saling pengertian dan memiliki pengetahuan yang sama. Salah satu ragam akrab yang akan dikaji dalampenelitian ini adalah ragam akrap dalam masyarakat Melayu jambi yang mengunakan bahasa Melayu Jambi.

Dalam komunikasi verbal masyarakat Melayu Jambi, variasi sapaan juga banyak ditemukan baik dalam wacana ragam akrab maupun ragam santai. Wacana ragam akrab dan ragam santai ini biasanya hanya dapat dimengerti oleh orang-orang yang sudah sering berinteraksi sehingga tidak terjadi kesalahpahaman antara kedua belah pihak yang berkomunikasi. Hal ini dapat dilihat pada contoh ungkapan: Hebat kau yo, Degil nian budak ko., awak tu pelit!. Contoh kalimat tersebut termasuk wacana ragam akrab sebagaimana yang dikemukakan Chaer. Analisis variasi sapaan ini terkait dengan kajian wacana oleh karena itu teori ini perlu dijelas.

Secara umum, wacana didefinisikan sebagai penggunaan bahasa dalam teks dan tuturan yang merupakan suatu bentuk yang dinamis dalam kehidupan sosial, jati diri, dan identitas seseorang (Phillips dan Jorgensen, 2002:114). Dalam kajian linguistik, ada tiga paradigma untuk menentukan konsep wacana. Menurut Schiffrin (1994:20) paradigma formalis, fungsionalis, dan formalis-fungsionalis. Menurut paradigma formalis, wacana dipandang sebagai 
unit bahasa di atas tataran kalimat karena secara hirarkis wacana dibangun oleh morfem yang kemudian membentuk kata, frasa, klausa, kalimat, dan wacana. Adapun, paradigma fungsionalis memandang wacana sebagai bahasa dalam pemakaiannya. Artinya, wacana dipandang sebagai suatu sistem sosial dan kultural yang diwujudkan melalui fungsifungsi bahasa. Wacana merupakan satuan bahasa yang lengkap dan tertinggi dalam hierarki gramatikal.

Dalam aktivitas sosial, bahasa berfungsi untuk memberi dan menerima informasi (Gee, 1999:1). Dikotomi paradigma formalis dan fungsionalis tentang tentang esensi wacana tidaklah dapat dipisahkan. Paradigma formalis dan fungsionalis kemudian dipadukan dalam konsep ujaran (utterance). Wujud dari ujaran bukanlah kalimat, melainkan satuan penggunaan bahasa (units of language use) dalam komunikasi. Dengan demikian, wacana bukan saja dipandang sebagai satuan bahasa di atas tataran kalimat atau penggunaan bahasa dalam komunikasi, melainkan koleksi kontekstual satuan penggunaan bahasa.

Analisis wacana adalah disiplin yang ditujukan untuk penyelidikan tentang hubungan antara bentuk dan fungsi dalam komunikasi verbal. Tujuan dari studi wacana adalah untuk menyediakan deskripsi yang jelas dari perbedaan sistematis dalam bentuk dan fungsi, serta hubungan antara keduanya (Renkema, 1993:1-3). Analisis wacana menurut Wood dan Kroger (2000:1-2) adalah perspektif tentang kehidupan sosial yang mengandung unsur metodologis dan konseptual. Analisis wacana melibatkan cara berpikir tentang wacana (elemen konseptual) dan cara memperlakukan wacana sebagai data (elemen metodologis). Potter (1997:146) menyatakan bahwa analisis wacana memiliki komitmen analitis untuk mempelajari wacana sebagai teks dan tuturan dalam praktek sosial karena fokus kajian tidak pada bahasa sebagai entitas abstrak seperti leksikon atau seperangkat aturan tata bahasa. Dengan demikian dapat disimpulkan bahwa fokus kajian wacana bukan saja dilakukan pada aspek struktur dan fungsi, melainkan pada ujaran sebagai konsep paduan antara struktur dan fungsi bahasa.

\section{METODE}

Metode penelitian yang digunakan terhadap bentuk variasi wacana ragam akrab bahasa Melayu Jambi metode deskriptif kualitatif dengan pendekatan etdografi komunikasi. Menurut Bogdan dan Taylor dalam Muhammad (2011:30) penelitian deskriptif kualitatif bertujuan untuk mendeskripsikan suatu peristiwa atau gambaran keadaan subjek, yang berada dalam lingkungan dan situasi tertentu. Penjelasan pada deskriptif kualitatif berbentuk deskripsi fenomena, tidak berupa angka-angka atau koefisien tentang hubungan antarvariabel.

Data dalam penelitian ini berupa wacana ragam akrab dan ragam santai masyarakat Melayu Jambi yang diperoleh dengan teknik Wawancara etnografi melalui langkah-langkah berikut: (1) menetapkan informan, (2) mewawancarai informan, (3) membuat catatan etnografis, (4) mengajukan pertanyaan deskriptif, (5) menganalisis wawancara etnografis, (6) membuat analisis domain, (7) mengajukan pertanyaan struktural, (8) membuat analisis taksonomik, (9) mengajukan pertanyaan kontras, (10) membuat analisis komponen, (11) menemukan tema-tema budaya, dan (12) menulis laporan etnografi. Data primer dalam penelitian diperoleh dari informan yang berasal dari kota jambi dan kabupaten Muaro Jambi. Informan ditetapkan berdasarkan arah mata angin. Rincian informan yang menjadi subjek penelitian yaitu masing-masing 2 orang dari Barat, Timur, utara, dan selatan, serta ditambah 2 orang dari pusat kota tempat penelitian. Informan yang dipilih harus memenuhi kriteria yang telah ditetapkan yakni terandalkan, dapat dipercaya baik dari segi pengetahuan maupun kejujuran secara umum dan secara khusus dalam memberikan data yang akurat. (Djajasudarma, 2006:22).

\section{HASIL DAN PEMBAHASAN}

Sesuai pertanyaan penelitian dan hasil analisis data, maka ditemukan bahwa ada variasi sapaan wacana ragam ragam akarab dan santai ditemukan dalam keluarga dan teman akrab. Variasi sapaan dalam keluarga meliputi: 1) terhadap keluarga yang lebih tua, 2) terhadap keluarga lebih muda, dan 3) terhadap sesama besar/pasangan. Sedang variasi sapaan di luar keluarga ditemukan pada komunikasi verbal antarteman karib yakni teman yang benar-benar dekat atau akrab.

Selain itu, hasil penelitian yang terkait pola kalimat dari kedua ragam ditemukan kalimat yang pendek-pendek. Kalimat ragam akrab lebih cendrung berpola Subjek-Predikat dan ragam santai cendrung berpola Predikat--Objek (P-O-K). Secara rinci hasil penelitian akan dibahas sebagai berikut.

\section{Variasi wacana ragam akrab dan ragam santai terhadap orang yang lebih tua}

Variasi wacana ragam akrab dan santai terhadap orang yang lebih tua terdiri atas variasi wacana ragam akrab dan santai terhadap kakek, nenek, ayah, ibu, mertua, kakak, paman, bibi, dan kakak. Untuk lebih jelasnya dapat dilihat pada penjelasan berikut ini. Perbedaan Wacana ragam akrab dan santai terhadap ayah dalam Bahasa Melayu Jambi di Desa Mendalo Indah Muarojambi dapat dilihat pada percakapan berikut. 
Tabel. 1

Percakapan Ragam Akrab dan Ragam Santai Terhadap Ayah

\begin{tabular}{|c|c|}
\hline \multicolumn{1}{|c|}{ Ragam Akrab } & Ragam Santai \\
\hline Anak : Bak duet & Anak : Bak mintak duet \\
'Bapak uang' & 'Bapak minta uang' \\
Ayah : Meli apo? & Ayah : nak meli apo kau? \\
'Membeli apa? & 'Mau membeli apa? \\
Anak : Meli jajan & Anak : Meli jajan \\
'Membeli jajan' & 'Membeli jajan' \\
Ayah : Jajan bae, tu Nasi belambun di & Ayah : Ngapo anak bajajan bae, tu \\
dapur tu. 'Nasi banyak di dapur' & Nasi belambun di dapur. tu \\
& 'Mau membeli jajan saja, Nasi \\
& banyak di dapur itu' \\
\hline
\end{tabular}

Lokasi: di depan rumah

Informan; Ayah dan anak

Variasi Ragam akrab tersebut terjadi antara anak dan ayah. Tanpa mengatakan minta uang kepada ayah dengan cukup mengatakan Bak duet 'Bapak uang' ayah sudah mengerti jika anaknya meminta uang, ayah tidak mau memberikan uang seperti permintaan anaknya cukup dengan mengatakan Nasi belambun di dapur tu 'Nasi banyak di dapur itu' dan si anak sudah mengerti dengan maksud perkataan itu bahwa jika ia lapar nasi ada nasi di dapur dan ayahnya tidak mau memberikan uang kepadanya. Berbeda dengan ragam santai yang sedikit memiliki kejelasan dalam kalimatnya dibandingkan ragam akrab. Kata Mintak 'Minta' pada kalimat Bak, Mintak duet 'Bapak, Minta uang' menunjukkan bahwa kalimat tersebut formal karena lebih lengkap. Kata Nak bejajan manjang be 'Mau membeli jajan saja' pada kalimat Nak bejajan manjang be, Nasi belambun di dapur tu 'Mau membeli jajan saja, Nasi banyak di dapur itu' menunjukkan bahwa kalimat tersebut santai karena lebih lengkap dibandingkan yang akrab.

\section{Variasi wacana ragam akrab terhadap yang Lebih Muda}

Sapaan ragam akrab terhadap yang lebih muda terdiri atas variasi wacana ragam akrab terhadap anak, cucu, cicit, ponakan, dan variasi wacana ragam akrab terhadap menantu. Variasi ragam akrab terhadap anak dalam Bahasa Melayu Jambi di Desa Mendalo Indah Muarojambi dapat dilihat pada percakapan berikut ini.

Tabel 2.

Percakapan Ragam Akrab Terhadap Anak

\begin{tabular}{|l|l|}
\hline \multicolumn{1}{|c|}{ Ragam Akrab } & \multicolumn{1}{|c|}{ Arti kalimat } \\
\hline Ayah : lah tu maine lup, ari lah senjo & 'Sudahlah mainnya nak, hari sudah sore' \\
Anak : Iyo Bi, ko nak mandi la & 'Ya, ayah ini sudah mau mandi' \\
Ayah : Jangan lupo semanyang yo. & 'Jangan lupa sholat yo anak' \\
Anak : Iyo Bi! & 'Iya ayah' \\
Ayah : Kagek bilang mak Kau, Abi ke & 'Nanti sampaikan ke ibumu, Ayah ke \\
mesjid yo! & mesjid!' \\
\hline
\end{tabular}

Lokasi: di dalam rumah

Informan; Ayah dan anak

Dalam kutipan percakapan di atas terdapat variasi sapaan dalam ragam akrab antara anak dan ayah dan anak. Variasi sapaan dalam wacana tersebut ada yang berasal dari kosa kata bahasa Melayu Jambi yakni Lup atau kulup yang disingkat Lup. Kulup atau lup adalah kosakata bahasa Melayu Jambi untuk memanggil anak laki laki yang disayangi. Situasi komunikasi lancar dan penuh keakraban, sehingga wcana ini masuk jenis wacana ragam akrab. Begitu pula adari aspek isi komunikasi terlihat tidak terjadinya kesalahpahaman pengertian antara ayah dan anak. Dalam percakapan pertama, Anak mendengar peringatan ayahnya mengucapkan Sudha la maine tu lup, ari la senjo 'Sudahlah bermainnya, hari sudah sore' anaknya sudah mengerti jika dirinya disuruh mandi oleh ayahnya sesuai dengan kebisaan dalam keluarga terbut. Jadi walaupun Ayahnya tidak mengucapkan kalimat Cepatlah mandiBerbeda dengan ragam santai yang sedikit memiliki kejelasan dalam kalimatnya dibandingkan ragam akrab. Kata Mandilah lagi 'Cepat mandi' pada kalimat Suda la maine tu, Ari la senjo, Mandilah lagi' Sudahlah bermainnya, hari sudah sore, Cepat mandi’ menunjukkan bahwa kalimat tersebut santai karena lebih lengkap dibandingkan yang akrab. 
Ade Rahima, Variasi Sapaan Ragam Akrab dan Ragam Santai Masyarakat Melayu Jambi dalam Komunikasi Verbal (Kajian Sosiolinguistik)

\section{Variasi Sapaan Ragam Akrab Terhadap Cucu}

Sapaan ragam akrab terhadap cucu dalam Bahasa Melayu Jambi di Desa Mendalo Indah Kecamatan Jambi Luar Kota Kabupaten Muarojambi dapat dilihat pada contoh berikut ini.

Tabel. 3

Percakapan Ragam Akrab Terhadap Cucu

\begin{tabular}{|c|c|}
\hline Nyai : & $\begin{array}{l}\text { Nyai Ado dak nengok suri. } \\
\text { yut? 'Ada melihat sisir Nenek } \\
\text { tidak Cu' }\end{array}$ \\
\hline Cucu & $\begin{array}{l}\text { :Dak Nyai } \\
\text { 'Tidak Nek' }\end{array}$ \\
\hline Nyai: & $\begin{array}{l}\text { Kalu gatal tenga belakang tu } \\
\text { biak Awak gaut } i \\
\text { 'Kalau punggung Nenek gatal } \\
\text { biar saya bantu menggaruknya' }\end{array}$ \\
\hline
\end{tabular}

Nyai : Nyai Ado dak nengok suri. yut? 'Ada melihat sisir Nenek dak $\mathrm{Cu}^{\prime}$

'Tidak Nek'

biak Awak gaut $i$

biar saya bantu menggaruknya'
Nyai : Ado nengok suri Nyai dak

yut? Nyai nak ngaut tenga

belakang Nyai ko ha

'Ada melihat sisir Nenek tidak

$\mathrm{Cu}$, Nenek mau menggaruk punggung Nenek'

Cucu : Dak Nyai

'Tidak Nek'

Kalu gatal tenga belakang tu

biak Awak gaut $i$

'Kalau punggung Nenek gatal

biar saya bantu menggaruknya'

Tempat: Lokasi percakapan di rumah keluarga

Situasi: Akrab dan Santai

Peserta tutur: Nenek dengan cucu.

Dari percakapan di atas telah ada ragam akrab antara nenek dan cucu. Ragam akrab tersebut dapat dilihat dari tidak terjadinya kesalahpahaman pengertian dalam komunikasi keduanya. Dengan hanya menanyakan sisir rambut si cucu sudah mengerti jika sisir rambut itu untuk menggaruk punggung nenek maka cucu mengatakan Kalu gatal tenga belakang tu biak Awak gaut $i$ 'Kalau punggung Nenek gatal biar saya bantu menggaruknya'. Berbeda dengan ragam santai yang sedikit memiliki kejelasan dalam kalimatnya dibandingkan ragam akrab. Kata Nyai nak ngaut tenga belakang Nyai ko ha 'Nenek mau menggaruk punggung Nenek' pada kalimat Ado nengok suri Nyai dak Cung? Nyai nak ngaut tenga belakang Nyai ko ha 'Ada melihat sisir Nenek tidak $\mathrm{Cu}$, Nenek mau menggaruk punggung Nenek' menunjukkan bahwa kalimat tersebut santai karena lebih lengkap dibandingkan yang akrab.

Dari percakapan di atas telah ada ragam akrab antara istri dan suami. Ragam akrab tersebut dapat dilihat dari tidak terjadinya kesalahpahaman pengertian dalam komunikasi keduanya. Mendengar istrinya mengatakan bawang dan uang jajan untuk anak sudah habis suami mengerti jika pernyataan tersebut berarti istrinya minta uang belanja, lalu sang suami mengiyakan seraya mengingatkan istrinya agar tidak boros karena minggu depan angsuran bank sudah menunggu. Berbeda dengan ragam santai yang sedikit memiliki kejelasan dalam kalimatnya dibandingkan ragam akrab. Kata Mintak duet 'Minta uang' pada kalimat Mintak duet Bak Tipa, Bawang dak tek gi di dapur tu, jajan budak sekolah besok pagi la abis go la 'Minta uang Yah, Bawang tidak ada lagi di dapur, uang jajan anak sekolah untuk besok juga sudah habis' menunjukkan bahwa kalimat tersebut santai karena lebih lengkap dibandingkan yang akrab.

\section{Variasi Ragam Akrab dan Santai Antarteman Karib}

Variasi ragam akrab dan ragam santai antarteman merupakan bentuk variasi wacana antara sesama besar/seumur. Variasi ini terjadi terhadap teman yang benar-benar akrab atau kawan karib. Variasi wacana ragam akrab dan ragam santai antarteman karib dapat dilihat pada percakapan berikut:

Tabel 4.

\section{Percakapan Ragam Akrab Antarteman Karib}

A : Kemano Es? 'Kemana teman?'
B : Ke ulu 'Ke hulu teman'
A : Apo hal e? 'Ada apa?'
B : Dak e la 'Tidak ada apa-apa'

A: nak kemano jok? 'Mau kemana teman?'

B: Nak ke ulu jok 'Mau ke hulu teman'

A: Apo hal e? 'Ada apa?'

B : Tidak e la jok 'Tidak ada apa-apa teman'

Lokasi: di jalan desa

Informan; dua orang remaja yang tidak ada hubungan keluarga.

Percakapan di atas diakukan di jalan oleh penutur yang sebaya. Walaupun kalimatnya singkat tapi tetap bersifat komunikatif. Tidak terdapat kesalahpahaman atau kecanggungan antar penutur dan penangap tutur dsnsebaliknya 
kelihatan akrab. Wacan tersebut dapat digolongkan ragam akrab dapat diperkuat oleh situasi komunikasi. Melihat teman akrabnya melewati depan rumahnya, teman 1 bertanya hanya dengan dengan mengunakan sapaan nama penaggap tuturnya (teman 2) serperti kutipan di atas: Kemano Es? 'Kemana teman (Es nama teman penutur). Teman yang ditanya langsung merespon dengan menjawab pertanyaan temannya yaitu: Ke ulu $D a$ 'ke hulu Ida'. Berbeda dengan ragam santai yang sedikit memiliki kejelasan dalam kalimatnya dibandingkan ragam akrab. Variasi sapaan mengunakan bahasa gaul (Jok untuk sapaan santai). Varisi ini ditentukan oleh faktor tempat dan topik tutur. Wancana ini masuk ke ragam santai karena pilihan sapaan yang akrab dan santai.

\section{SIMPULAN}

Berdasarkan hasil dan pembahasan analisis bentuk wacana ragam akrab dan ragam santai Bahasa Melayu Jambi di desa Mendalo Indah Muarojambi dapat diambil beberapa simpulan yaitu:

1. Variasi sapaan ragam akrab lebih cendrung terjadi jika antara menutur dan penutur memiliki hubungan yang sangat dekat yaitu anggota keluarga atau teman karib sedangkan ragam santai cendrung terjadi karena kebersamaan situasi dan tempat tuturan terjadi.Variasi wacana ragam akrab dan ragam santai antaranggota keluarga terdiri atas variasi wacana ragam akrab terhadap orang yang lebih tua, muda, dan wacana ragam akrab terhadap pasangan dan antarteman yang benar-benar akrab

2. Faktor penentu variasi sapaan wacana ragam akrab dan wacana ragam santai yaitu hubungan penutur dan petutur, situasi dan tempat tuturan, serta topik tuturan.

3. Pola kalimat ragam akrab dan ragam santai lebih singkat dengan pola Subjek-Predikat (S-P) sedangkan ragam santai Peredikat-Objek (P-O).

Penelitian ini baru penelitian pendahuluan sehingga hasilnya belum mendalam dan masih terbatas. Oleh karena itu disaran bagi peneliti lain untuk melakukan penelitian lanjutan yang lebih kompleks terhadap variasi percakapan ragam akrab dan santai dari berbagai pendekatan penelitian sehingga dapat menghasilkan teori baru

\section{DAFTAR PUSTAKA}

Chaer, Abdul, dkk. 2004. Sosiolinguistik Perkenalan Awal. Jakarta: PT Rineka Cipta.

Djajasudarma, Fatimah. 2006. Metode Linguistik. Jakarta: Pusat Pembinaan Bahasa.

Gee, James Paul, An Introduction to Discourse Analysis: Theory and Method, London: Routledge, 1999.

Phillips, Louise and Marianne W. Jorgensen, Discourse Analysis as Theory and Method, Thousand Oaks: Sage Publication, Inc., 2002.

Potter, J., "Discourse analysis as a way of analyzing naturally occuring talk". In D. Silverman (Ed.), Qualitative Research (pp. 144-160) London: Sage, 1997.

Renkema, Jan, Discourse Studies: An Introductory Textbook, Philadelphia: John Benjamin Publishing Company, 1993.

Schiffrin, Deborah, Discourse Markers, Cambridge: Cambridge University Press, 1987. , Approaches to Discourse, Cambridge: Blackwell Publishers, 1994.

Wood, Linda A., and Rolf O. Kroger, Doing Discourse Analysis: Methods for Studying Action in Talk and Text, Thousand Oaks: Sage Publication, Inc., 20 Alwi. 2001. Kamus Besar Bahasa Indonesia. Jakarta: Balai Pustaka.

Sedarmayanti, dkk. 2011. Metodologi Penelitian. Bandung: Bandar Maju.

Sudaryanto. 1993. Metode dan Aneka Teknik Analisis Data. Yogyakarta: Duta Wacana University Press. 